\title{
ANTIMICROBIAL EFFECTS OF TRIMETHOPRIM AND SULPHADIAZINE IN INFECTED URINE AND BLOOD
}

\author{
R. W. Lacey, J. G. Rogerson and Anne Stokes \\ Department of Bacteriology, North Cambridgeshire Hospital, Wisbech, Cambs.
}

THE USE of antimicrobial agents in combination continues to be evaluated for the ability to suppress the appearance of resistant bacterial mutants and to produce a synergistic effect in vivo. Both these properties were thought to apply to the use of a fixed combination of trimethoprim and sulphamethoxazole (co-trimoxazole). However, in the treatment of lower urinary-tract infections, there is evidence of the therapeutic effect being so dominated by trimethoprim that the potential synergistic effect between trimethoprim and sulphamethoxazole is not realised during clinical use (Brumfitt and Pursell, 1972; Koch et al., 1973; Anderson et al., 1974; Kasanen et al., 1974; Greenwood and O'Grady, 1976). Trimethoprim has also been used in combination with sulphadiazine (Männistö et al., 1973; Grey and Hamilton-Miller, 1977; Tuomisto, Kasanen and Renkonen, 1977); this preparation (co-trimazine) contains in each tablet $90 \mathrm{mg}$ of trimethoprim and $410 \mathrm{mg}$ of sulphadiazine and the recommended dosage is one tablet twice daily. Any advantage for such a combination over the use of individual components should be clearly established because the toxic effects of sulphadiazine and trimethoprim in a fixed combination seem likely to be greater than when they are used singly. During therapy, urine concentrations of active sulphadiazine can be anticipated to be higher than those of sulphamethoxazole on account of the lesser acetylation and higher solubility of sulphadiazine (e.g., Tuomisto et al., 1977). Thus, while we have previously failed to detect any synergistic effects between sulphamethoxazole and trimethoprim when added in therapeutic levels to naturally infected urine (Stokes and Lacey, 1978), sulphadiazine might be present in sufficient amounts for synergy to occur. Therefore, experiments were performed to determine whether such synergy had occurred. This paper describes the antibacterial effects of these agents in urine and in blood, and investigation of the possibility that trimethoprim resistance appears during exposure of organisms to trimethoprim in urine.

\section{MATERIALS AND METHODS}

Culture media, general bacteriological methods and sensitivity testing were as as described by Stokes and Lacev (1978).

Infected urine. Two types of infected urine were used. The first type consisted of small pools

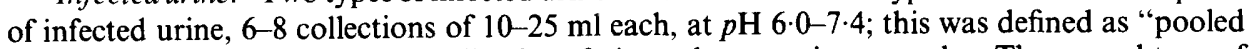
urine" and was used to dilute possible interfering substances in a sample. The second type of 
infected urine was obtained from each of 20 patients with untreated urinary-tract infection ("single urine"). All the urine samples contained pus cells $>500 / \mathrm{mm}^{3}$ and no antibacterial agent as shown by plate assay, were filtered and checked for sterility, and were stored as previously described by Stokes and Lacey (1978).

The pooled-urine collections were used in the tests for the antibacterial effects of a wide range of concentrations of trimethoprim (T) and sulphadiazine (SZ), alone and in combination, against a single test culture (Escherichia coli strain C13), and were also used in tests to examine the effects of inoculum size on the activities of these agents. At least one control urine, containing the test organisms but no antibacterial agent, was included in each experiment.

The $p \mathrm{H}$ of each the single urine samples was determined with a $p \mathrm{H}$ meter (Sandoz AVL, 42 Somers Road, Rugby) before and after each experiment. T was added to give a final concentration of $100 \mu \mathrm{g} / \mathrm{ml}$ and SZ to give $1000 \mu \mathrm{g} / \mathrm{ml}$-urinary concentrations not likely to be exceeded with normal therapy. Portions of each urine also contained both of these substances or no antibacterial additives. One of two fully sensitive strains of $E$. coli (strains $\mathrm{C} 13$ as above and C6), against which $\mathrm{T}$ and $\mathrm{S}$ showed synergy in Oxoid Diagnostic Sensitivity Test (DST) Agar in the above ratio of $\mathrm{T}: \mathrm{SZ}(1: 10)$, was added from a broth culture to give a final cell density of $10^{6}-10^{7} / \mathrm{ml}$. A high bacterial density was used to permit the appearance of resistant mutants if they occurred, and to reflect the numbers present in acute untreated urinary-tract infection. Some experiments were also performed with an inoculum of $\sim 10^{3} / \mathrm{ml}$ of organisms that had been previously washed in saline, with essentially the same results (data not shown). The urine portions were then incubated at $37^{\circ} \mathrm{C}$ in 4-ml screw-capped bottles in an orbital incubator at 150 r.p.m. and samples were taken at 6 and $24 \mathrm{~h}$ for viable counts on the surface of Blood Agar Base (Mast Ltd, Liverpool) which contains adequate thymine and thymidine to inactivate residual antibacterial agents.

Indicator cultures for experiments with single urine were one or the other of two strains of $E$. coli (C6 or C13). Strain C6, in DST agar, was inhibited by SZ $10 \mu \mathrm{g} / \mathrm{ml}$ and by T $0.4 \mu \mathrm{g} / \mathrm{ml}$ singly, and by SZ $0.5 \mu \mathrm{g} / \mathrm{ml}$ combined with T $0.05 \mu \mathrm{g} / \mathrm{ml}$. Strain C13 was inhibited by SZ $20 \mu \mathrm{g}$ and T $0.6 \mu \mathrm{g} / \mathrm{ml}$ singly, and by SZ $2.5 \mu \mathrm{g} / \mathrm{ml}$ combined with T $0.25 \mu \mathrm{g} / \mathrm{ml}$.

Urine samples from individual patients were used to represent "natural urine". In these experiments, the drug concentrations were not varied.

Experiments were also performed with pooled uninfected urine (pus cells $<30 / \mathrm{mm}^{3}$; sterile) collected after routine laboratory screening, and in "artificial urine". The latter consisted of $\mathrm{NaH}_{2} \mathrm{PO}_{4} .2 \mathrm{H}_{2} \mathrm{O}, 5 \mathrm{~g} ; \mathrm{Na}_{2} \mathrm{SO}_{4}, 5 \cdot 3 \mathrm{~g} ; \mathrm{CaCl}_{2} .2 \mathrm{H}_{2} \mathrm{O}, 0.66 \mathrm{~g} ; \mathrm{MgCl}_{2} .6 \mathrm{H}_{2} \mathrm{O}, 0.85 \mathrm{~g} ; \mathrm{KCl}, 3 \mathrm{~g}$; urea, $20 \mathrm{~g}$; creatine, $4 \mathrm{~g}$; creatinine, $2 \mathrm{~g}$; human albumen $50 \mathrm{mg}$; glucose, $70 \mathrm{mg}$, distilled water to 1 litre. The urines were adjusted to $p \mathrm{H} 7.0$ by the addition of phosphate buffer.

Residual antibacterial substances were assayed on portions of urine by plate assay (Stokes and Lacey, 1978).

Possible development of trimethoprim resistance in urine. One colony from the 24-h sampling of the urine that had no added antibacterial agent and two colonies from each of the portions that contained trimethoprim were tested for the minimum inhibitory concentrations (MICs) of $\mathrm{T}$.

Reproducibility of methods. Whilst the rate of killing of a given culture by a constant concentration of drug varied slightly in the presence of different batches of blood or urine, replicate experiments for portions of a single fluid showed good reproducibility (coefficient of variation $30.2 \%$ in urine, $39.8 \%$ in blood).

Antibacterial effects of trimethoprim and sulphadiazine in human blood. Human blood was obtained either from a single donor under standard fasting conditions or from fresh (less than 7 days old) blood collected for transfusion; the former was delivered into lithium heparin; the latter was available because of incomplete collection, although it was at least $90 \%$ of the volume of a collection, and was collected into acid citrate dextrose at $p \mathrm{H} \mathrm{6.4-6.6}$. The antibacterial effects of $\mathrm{SZ}$ and $\mathrm{T}$ in heparinised or citrated blood were investigated with two strains of $E$. coli; one strain of Proteus and one of Staphylococcus aureus and when they were found to be identical all subsequent experiments were performed in citrated blood. From three to four units of blood of the same $\mathrm{ABO}$ groups collected in this way were combined and stored at $4^{\circ} \mathrm{C}$ for up to a week. From this pool, 10-ml portions were transferred to screw-capped containers for study of the action of $\mathrm{T}$ and $\mathrm{SZ}$. 
The cultures selected for studies with blood were those that had yielded high densities of bacteria $\left(>10^{7} / \mathrm{ml}\right.$ after $\left.24 \mathrm{~h}\right)$ on test culture in human blood. Some cultures required three passages in blood before they were considered suitable indicator strains.

Bactericidal activity was defined as a fall in viable counts to less than $10 \%$ of the inoculum. Bacteristatic action was defined as either no change in viable count or a small reduction to not less than $90 \%$ of the inoculum.

Attempts to select trimethoprim-resistant mutants in vitro. Four strains of E. coli which were sensitive to sulphonamides (MIC $<20 \mu \mathrm{g} / \mathrm{ml}$ ) and to T (MIC $\sim 0.2 \mu \mathrm{g} / \mathrm{ml}$ of DST agar) and four of $E$. coli sensitive to T and resistant to sulphonamides (MIC $>200 \mu \mathrm{g} / \mathrm{ml}$ ) were inoculated on DST-agar plates containing T $2,5,10,20,50 \mu \mathrm{g} / \mathrm{ml}$ with SZ at $0,5,10,20$ or $50 \mu \mathrm{g} / \mathrm{ml}$ respectively. About $10^{11}$ bacteria of each strain were inoculated on each of the plates, which were incubated for $72 \mathrm{~h}$ at $37^{\circ} \mathrm{C}$.

Other materials. Twenty-five strains of E. coli and 12 of Proteus vulgaris, all sensitive to SZ (MIC $<20 \mu \mathrm{g} / \mathrm{ml}$ ) and T (MIC $<0.5 \mu \mathrm{g} / \mathrm{ml}$ ), and eight strains of Streptococcus faecalis resistant to sulphonamides (MIC $<200 \mu \mathrm{g} / \mathrm{ml}$ ) and sensitive to T (MIC $<1.0 \mu \mathrm{g} / \mathrm{ml}$ ) were obtained from the urine of patients with proven urinary-tract infections.

Trimethoprim lactate was supplied by Burroughs Wellcome Ltd, Beckenham, Kent and sodium sulphadiazine by May and Baker Ltd, Dagenham, Essex.

\section{RESULTS}

Effect of different concentrations of trimethoprim and sulphadiazine in pooled infected urine

$\mathrm{T}$ and $\mathrm{SZ}$ were added to 4-ml portions of filtered infected urine either singly or combined in $\mathrm{T}: \mathrm{SZ}$ ratios, respectively, of $1: 1,1: 2$, or $1: 10$ over a range of $\mathrm{T} 0 \cdot 5$ $\mu \mathrm{g}$ to $\mathrm{T} 100 \mu \mathrm{g} / \mathrm{ml}$. Pooled urine was used to reduce some of the variables. The test culture was $E$. coli strain C13. During 6 and $24 \mathrm{~h} \mathrm{~T}$ alone produced either a static or cidal effect at all concentrations from 2 to $100 \mu \mathrm{g} / \mathrm{ml}$ $(2,5,10,15,25,50,100 \mu \mathrm{g} / \mathrm{ml})$. The rate of killing was no greater at the higher concentrations than at the lower. At all concentrations of SZ (0.5-1000 $\mu \mathrm{g} / \mathrm{ml}$ ) there was some multiplication of the test organism at 6 and $24 \mathrm{~h}$ but usually to a smaller extent than in the control.

The inhibitory effect of $\mathrm{T}$ at $2-100 \mu \mathrm{g} / \mathrm{ml}$ was not enhanced by the presence of SZ at any of the three $\mathrm{T}: \mathrm{SZ}$ ratios used.

With $\mathrm{T}$ at $1.0 \mu \mathrm{g}$ and $0.5 \mu \mathrm{g} / \mathrm{ml}$, the presence of SZ at $10 \mu \mathrm{g}$ and $5 \mu \mathrm{g}$ respectively potentiated the effect of $T$ at $24 \mathrm{~h}$ but not at $6 \mathrm{~h}$ (data not shown). Sixteen different indicator strains, 12 E. coli and four Proteus vulgaris, were examined in pooled urine containing T or SZ $25 \mu \mathrm{g}$ of each, either singly or combined. As with the test culture $\mathrm{C} 13$ (see above), the activity of $\mathrm{T}$ appeared dominant, in that all the growth of these cultures was inhibited by $\mathrm{T}$ and the addition of $\mathrm{SZ}$ did not increase the inhibition. Inhibition by $\mathrm{T}$ ranged from a fall in viable counts ranging from $4 \times 10^{0}$ to $3 \times 10^{2}$-fold at $6 \mathrm{~h}$ and from $1.0 \times 10^{1}$ to $6.8 \times 10^{3}$-fold at $24 \mathrm{~h}$. As above, 12 cultures multiplied (by $\sim 1.6 \times 10^{0}-4.7 \times 10^{2}$-fold) at 6 and at $24 \mathrm{~h}$ in the presence of SZ. One culture of E. coli was killed by SZ, and the other three showed a bacteristatic effect.

\section{Effect of inoculum size on antibacterial action of trimethoprim and sulphadiazine in infected urine}

The relatively poor activity of SZ in infected urine might be due to the addition 


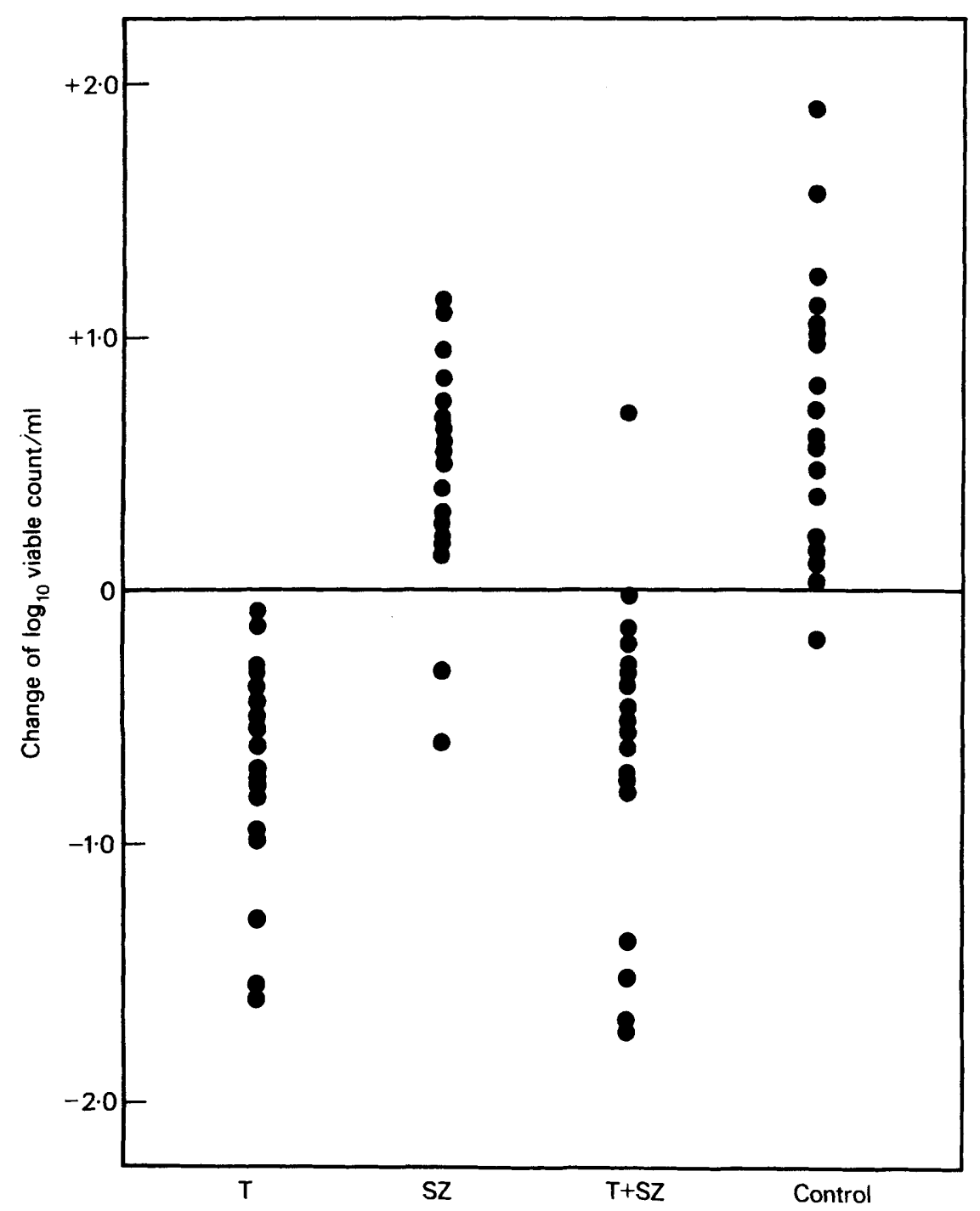

FIG. 1-Changes in viable counts, during $6 \mathrm{~h}$, of two sensitive strains of Escherichia coli after addition to portions of filtered infected urine. $\mathrm{T}=$ trimethoprim $100 \mu \mathrm{g} / \mathrm{ml}, \mathrm{SZ}=$ sulphadiazine $1000 \mu \mathrm{g} / \mathrm{ml}$, $\mathrm{T}+\mathrm{SZ}=\mathrm{a}$ combination of trimethoprim $100 \mu \mathrm{g} / \mathrm{ml}$ and sulphadiazine $1000 \mu \mathrm{g} / \mathrm{ml}$. Control denotes addition of test organisms but no antibacterial agent.

of p-amino benzoic acid with the test culture. To test for this possibility, cultures of E. coli strain $\mathrm{C} 13$ were centrifuged and washed twice and resuspended in a $0.9 \%(\mathrm{w} / \mathrm{v})$ solution of $\mathrm{NaCl}$. Dilutions of this were added to one of two pools of infected urine, and SZ was added to give final concentrations of $1-1000 \mu \mathrm{g} / \mathrm{ml}$. Final bacterial densities ranged from $10^{3}$ to $10^{7} / \mathrm{ml}$. With all these inocula, SZ had little effect; the $E$. coli multiplied at each concentration. 
Effect of trimethoprim and sulphadiazine in samples of urine from single patients

Against E. coli strains C6 and C13, T $100 \mu \mathrm{g} / \mathrm{ml}$ alone produced an effect that ranged from an obviously bactericidal action to a bacteristatic one (figs. 1 and 2) as previously reported (Stokes and Lacey, 1978). The effect of SZ 1000 $\mu \mathrm{g} / \mathrm{ml}$ alone ranged from apparently no antibacterial activity in the majority of urines to a bactericidal action in three at $24 \mathrm{~h}$ (figs. 1 and 2). The presence of $\mathrm{T}$ $100 \mu \mathrm{g} / \mathrm{ml}$ and SZ $1000 \mu \mathrm{g} / \mathrm{ml}$ together produced an effect not significantly different from that of $\mathrm{T}$ alone at either sampling time: at $6 \mathrm{~h}, t=0.5, \mathrm{p}>0.5$; at $24 \mathrm{~h}, t=0.09, \mathrm{p}>0.5$ ).

The variable antibacterial effect of $\mathrm{T}$ was not due to alteration of $p \mathrm{H}$

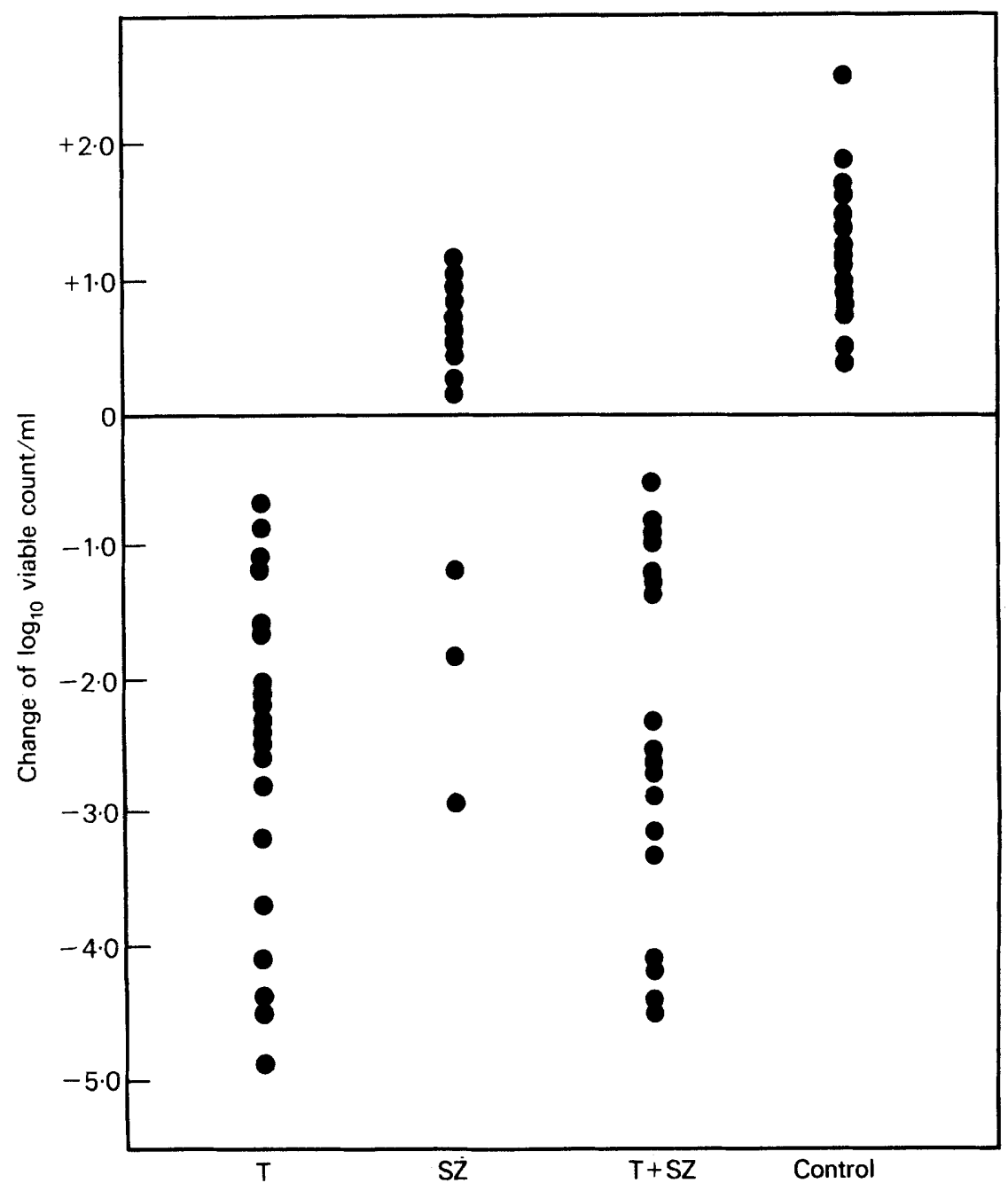

FIG. 2-Changes in viable counts during $24 \mathrm{~h}$ of two sensitive strains of $E$. coli after addition to portions of filtered infected urine. $\mathrm{T}=$ Trimethoprim $100 \mu \mathrm{g} / \mathrm{ml}, \mathrm{SZ}=$ sulphadiazine $1000 \mu \mathrm{g} / \mathrm{ml}, \mathrm{T}+\mathrm{SZ}=\mathrm{a}$ combination of trimethoprim $100 \mu \mathrm{g} / \mathrm{ml}$ and sulphadiazine, $1000 \mu \mathrm{g} / \mathrm{ml}$. Control denotes addition of test organisms but no antibacterial agents. 


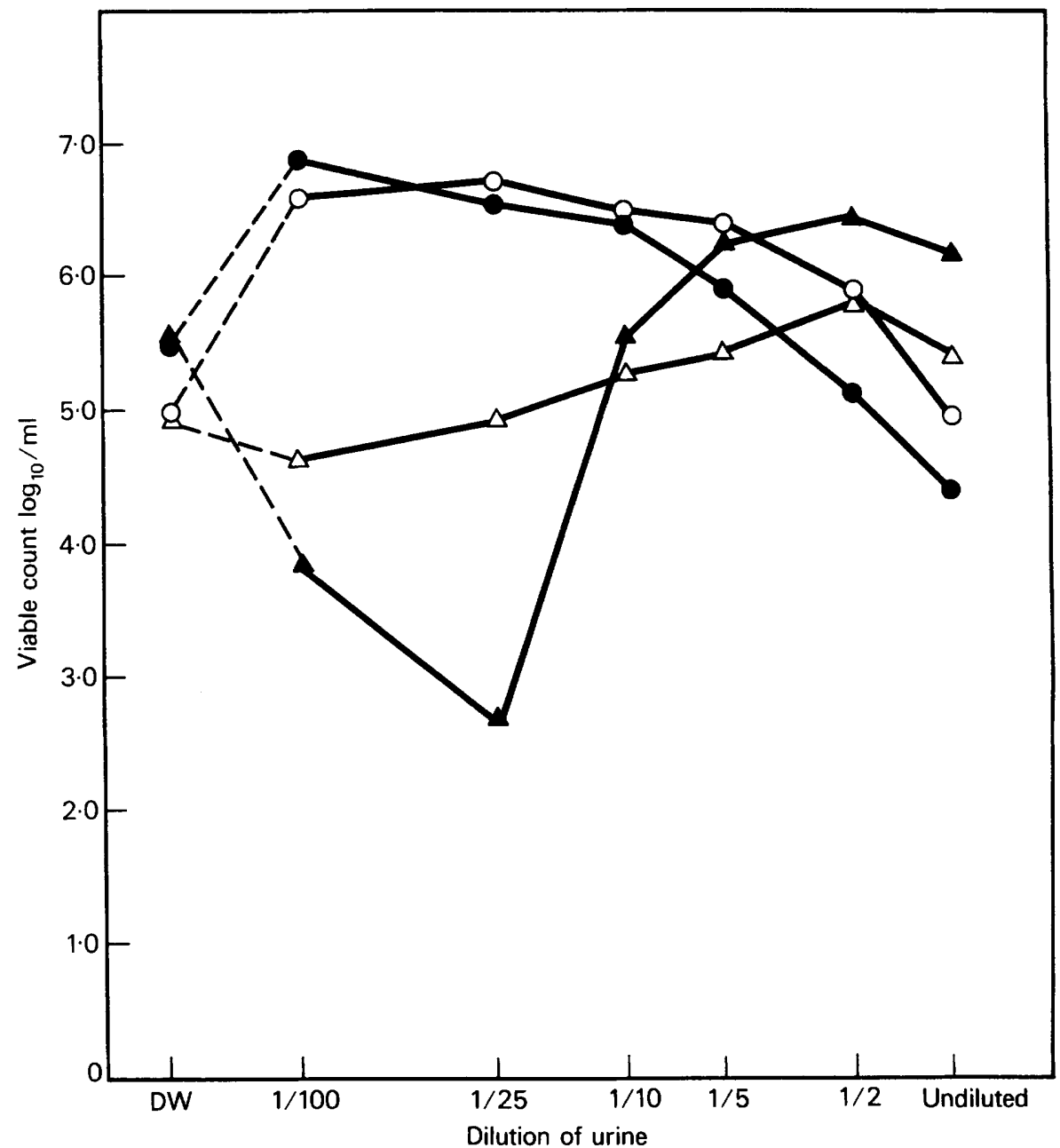

FIG. 3.-Changes in viable counts during 6 and $24 \mathrm{~h}$ after the addition of bacteria to either pooled uninfected urine or artificial urine, each at different dilutions in distilled water. $\mathrm{DW}=$ Distilled water alone. $\Delta-\Delta=$ Artificial urine during $6 \mathrm{~h} ; \Delta-\Delta=$ artificial urine during $24 \mathrm{~h} ; \circ-0=$ pooled uninfected natural urine during $6 \mathrm{~h} ; \bullet=$ pooled uninfected natural urine during $24 \mathrm{~h}$.

because, although the initial $p \mathrm{H}$ of urine ranged from 5.03 to 8.23 and the final from $5 \cdot 11$ to $8 \cdot 22$, there was no correlation between the type of antibacterial effect and either initial $p \mathrm{H}$ or $p \mathrm{H}$ changes. However, on the three occasions when a bactericidal effect was seen with $\mathrm{SZ}$, the initial and final $p \mathrm{H}$ were near neutral or alkaline: initial $8 \cdot 23,7 \cdot 21,6 \cdot 32$; final $8 \cdot 15,7 \cdot 20,7 \cdot 18$.

Because of the failure of SZ to inhibit the growth of the test organisms in many of the urines, similar experiments were performed with various fluid media, including uninfected urine and artificial urine at differing $p \mathrm{H}$. We have so far been unable to identify the factors responsible for determining the degree of the antibacterial activity of SZ in urine. For example, optimal antibacterial activity of SZ in uninfected urine and artificial urine occurred at different 
dilutions of these fluids (fig. 3). After 24-h incubation, residual antibacterial agents, either singly or in the combination, were always present in at least $50 \%$ of the original concentration.

The MICs of T for all the colonies of E. coli recovered from each of the urines containing $\mathrm{T}$ did not differ from those recovered from the control urines. Thus, exposure of acteria to $T$ in the urinary tract is unlikely to be particularly associated with the development of resistance.

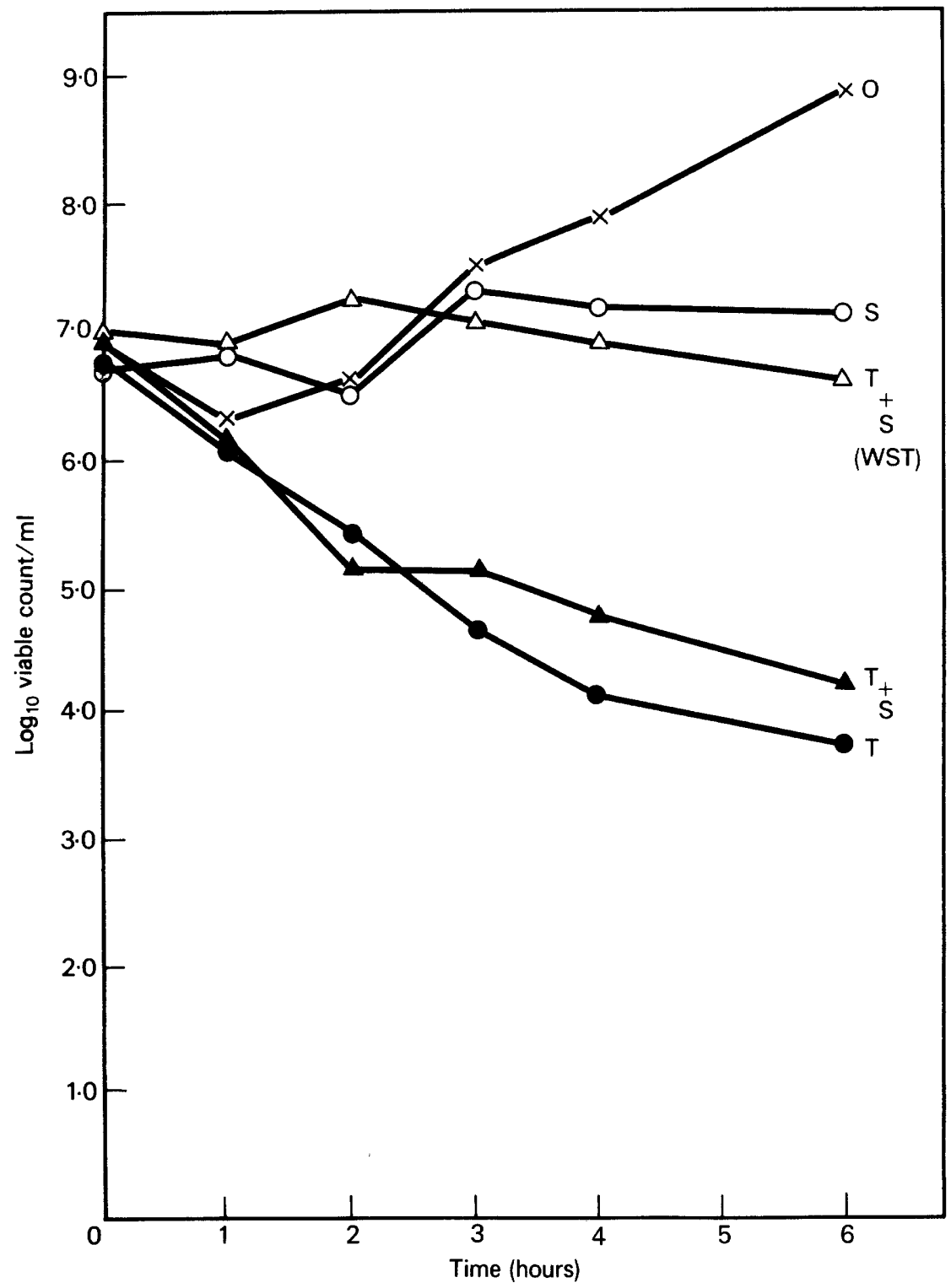

FIG. 4.-Effect of trimethoprim (T) $2 \mu \mathrm{g} / \mathrm{ml}$, sulphamethoxazole (S) $40 \mu \mathrm{g} / \mathrm{ml}$ and the combination on the growth of $E$. coli strain C 6 in blood and in Wellcotest Broth (WST). $\circ=$ No antibacterial drug; other symbols as in fig. 3 . 


\section{Activity of trimethoprim and sulphadiazine in human blood}

In urine obtained from patients with acute urinary-tract infections, the addition of SZ has little activity, presumably due to the presence of thymine and other antagonists (Stokes and Lacey, 1978, see above). Uninfected human serum contains low levels of thymidine - about $0.01 \mu \mathrm{g} / \mathrm{ml}$ (Nottebrock and Then, 1977); sulphonamides might therefore increase the antibacterial effect of $\mathrm{T}$ in human blood.

Five strains of E. coli, fully sensitive in Oxoid DST Broth to T and to SZ and to the combination (MICs: $\mathrm{T}<1 \mu \mathrm{g} / \mathrm{ml}, \mathrm{SZ}<20 \mu \mathrm{g} / \mathrm{ml}$, and $\mathrm{T}<0 \cdot 12$ combined with SZ $2.5 \mu \mathrm{g} / \mathrm{ml}$ ), combined with SZ $2.5 \mu \mathrm{g} / \mathrm{ml}$ ), and $S$. aureus strain S3 (MICs in DST: SZ $20 \mu \mathrm{g} / \mathrm{ml}, \mathrm{T} 0.5 \mu \mathrm{g} / \mathrm{ml}$ and SZ $1 \mu \mathrm{g}$ combined with T $0.05 \mu \mathrm{g} / \mathrm{ml}$ ) were incubated for $6 \mathrm{~h}$ in blood and Wellcotest Broth in the presence of SZ $40 \mu \mathrm{g}$ or T $2 \mu \mathrm{g}$ singly or with the two agents combined. The fluids were sampled hourly for numbers of viable organisms. As previously reported for the components of co-trimoxazole (Lewis, Anderson and Lacey, 1974), the combination of T with SZ produced a bacteristatic effect on these organisms in Wellcotest Broth but in parallel experiments in blood produced, surprisingly, a bactericidal effect for each strain inoculated. Experiments with sulphamethoxazole (S) rather than SZ produced a similar effect (fig. 4). SZ and $S$ were bacteristatic for each of the cultures during $6 \mathrm{~h}$. The addition of either SZ or S to T did not enhance the bactericidal effect of the latter.

When experiments in blood were extended to $24 \mathrm{~h}, \mathrm{~T} 1.0 \mu \mathrm{g} / \mathrm{ml}$ and SZ 20 $\mu \mathrm{g} / \mathrm{ml}$ were bactericidal against the majority of strains of $E$. coli, and T killed a proportion of Proteus and S. faecalis strains (table). The combination of T 0.5 $\mu \mathrm{g} / \mathrm{ml}$ and SZ $10 \mu \mathrm{g} / \mathrm{ml}$ produced bactericidal effects comparable to that of $\mathrm{T}$ alone.

At lower concentrations, T 0.5-0.01 $\mu \mathrm{g} / \mathrm{ml}$ and SZ $10 \mu \mathrm{g}-0.2 \mu \mathrm{g} / \mathrm{ml}$ were bactericidal only for $E$. coli. Of the 25 strains, 9 were killed by T $0.05 \mu \mathrm{g} / \mathrm{ml}$, a concentration a quarter or less of the MIC in DST agar. Five strains were killed by SZ 1-2.5 $\mu \mathrm{g} / \mathrm{ml}$, between one half and one fifth of the MIC. Combinations of T $0.01-0.025 \mu \mathrm{g} / \mathrm{ml}$ with SZ 0.2 or $0.5 \mu \mathrm{g} / \mathrm{ml}$, concentrations less than the MBCs in blood, produced a synergistic effect against 11 of these strains.

TABLE

Bactericidal action of trimethoprim, sulphadiazine, and the combination of both in human blood on urinary pathogens during $24 \mathrm{~h}$

\begin{tabular}{lcccc}
\hline \multirow{2}{*}{ Organism } & $\begin{array}{c}\text { Number } \\
\text { of strains } \\
\text { tested }\end{array}$ & $\begin{array}{c}\text { trimethoprim } \\
1 \mu \mathrm{g} / \mathrm{ml}\end{array}$ & $\begin{array}{c}\text { sulphadiazine } \\
20 \mu \mathrm{g} / \mathrm{ml}\end{array}$ & $\begin{array}{c}\text { Number of strains killed by } \\
+ \text { sulphadiazine } 10 \mu \mathrm{g} / \mathrm{ml}\end{array}$ \\
\hline $\begin{array}{l}\text { Escherichia coli } \\
\text { Proteus vulgaris }\end{array}$ & 25 & 23 & 16 & 20 \\
Streptococcus faecalis & 12 & 4 & 0 & 7 \\
\hline
\end{tabular}

$\mathrm{NT}=$ Not tested because of intrinsic high-level resistance. 
Throughout these experiments the concentrations of either SZ or $\mathrm{T}$ required for bacteristatic effect was always close to that required for cidal actions. When a bactericidal action was seen, the blood was usually sterile. Thus, in human blood, $\mathrm{T}$ and $\mathrm{SZ}$ singly produced predominantly bactericidal effects at therapeutic concentrations against urinary pathogens. Synergistic effects were seen only at low concentrations that were probably subtherapeutic.

\section{Attempts to isolate stable mutants resistant to $S Z$ and $T$ in vitro}

Despite the use of large inocula, a range of test cultures, and a range of drug concentrations, we have been unable to isolate, in one step, E. coli with a high and stable resistance to trimethoprim. Slow-growing colonies appeared at a frequency of $10^{-7}$, and rapidly gave rise on subculture to colonies fully sensitive to $T$. These colonies were seen at similar frequencies in sulphonamide-resistant and sulphonamide-sensitive cultures, and on media containing SZ and T combined or T alone.

\section{Discussion}

These experiments extend our previous observations (Anderson et al., 1974; Stokes and Lacey, 1978) that the antibacterial effects of sulphonamides and trimethoprim vary considerably with the bacterial strains and environments studied. Both agents reduce bacterial tetrahydrofolic acid which is an essential co-factor for synthesis of thymine - a component of nucleic acidsand also for the synthesis of some aminoacids, e.g., serine and methionine (Hitchings, 1970). Cells treated with inhibitory concentrations of these agents may undergo thymineless death, with thymine starvation causing prophage induction, single-strand breaks in DNA, premature initiation of replication, abnormal cell elongation, and elimination of $\mathbf{R}$ plasmids (Buick and Harris, 1975; Pinney et al., 1977). No single point of action can explain all these phenomena; more than one mechanism may destroy a specific culture, with the mode of death differing between cultures (Aizenberg, Samoylenko and Fradkin, 1977; Samanta and Bhattacharjee, 1977). Furthermore, thymineless death is affected by the composition of the medium; e.g., the presence of uridine (Amyes and Smith, 1978). Thus some of our observed variation in the antibacterial effects of $\mathrm{T}$ and $\mathrm{SZ}$ in human fluids may be due to these differences.

The experiments described here show that with $\mathrm{T}$ concentrations of $100 \mu \mathrm{g}$ and $2 \mu \mathrm{g} / \mathrm{ml}$ - the therapeutic range - the addition of SZ in various concentrations does not potentiate the antibacterial effect of $T$ in infected urine. Presumably, after thymineless death has been induced, the addition of SZ or excess T is superfluous; $\mathrm{T} 100 \mu \mathrm{g} / \mathrm{ml}$ produced an effect similar to that of 2 $\mu \mathrm{g} / \mathrm{ml}$. Bacteria surviving thymineless death at $24 \mathrm{~h}$ are not resistant variants, as judged by MIC estimation, but presumably represent the variable vulnerability of a large population of bacteria to thymine starvation.

The antibacterial effects of $\mathrm{T}$ and $\mathrm{SZ}$ in human blood differed from those in synthetic culture media. At therapeutic concentrations, both substances in 
blood were often bactericidal individually, but we could detect synergy only occasionally; this occurred with concentrations that were about one tenth the anticipated therapeutic concentration of co-trimazine from an adult daily dose of $180 \mathrm{mg}$ of $\mathrm{T}$ and $820 \mathrm{mg}$ of SZ.

It is not possible to extrapolate these findings directly to the therapy of urinary-tract infections, because these experiments were performed in batch cultures and do not include the influence of micturition and the possible antibacterial activity of the bladder mucosa. However, some clinical trials comparing the efficacy of $\mathrm{T}$ alone with $\mathrm{T}$ combined with a sulphonamide (see introduction) demonstrated no advantage from the addition of sulphonamide to $\mathrm{T}$; this was also demonstrated in vitro in our experiments with urine and with blood. It is reasonable to assume that the antibacterial effects of these substances in urinary-tract infections could be attributable to their activity in urine, blood and exudates from blood. The poor activity of SZ in natural and in artificial urine, with a frequently bactericidal effect in blood, suggest that at least some of the therapeutic activity of sulphonamides occurs in the presence of blood and its components. However, $\mathrm{T}$ alone produced a potent bactericidal action in blood against many urinary pathogens and an activity in urine that was either static or cidal. These findings support the suggestion that $T$ alone may be preferable to sulphonamide $+T$ combinations, because the use of the sulphonamide with $T$ can be expected to increase toxicity, cost and could also provoke additional resistance.

Although one of the properties thought to be associated with the use of $\mathrm{T}+$ sulphonamide mixtures is the suppression of resistance, there is no evidence for this during clinical use, and the combined preparation might select more resistance than individual drugs because the two drugs may not always be present at appropriate levels in the presence of commensal flora (Lacey, 1978). The origin of "chromosomal" resistance to T (e.g., Towner et al., 1978) is obscure; we have been unable to select from sensitive $E$. coli populations one-step T-resistant mutants that are not defective.

In contrast it is easy to show that with some antibacterial drugs, e.g., fusidic acid, novobiocin and rifampicin, stable resistant mutants are selected at high frequency; thus there may be a sound basis for the use of these agents in combination. But use of $\mathrm{T}$ is not specifically liable to select resistant mutants. Transferable $T$ resistance could be a theoretical reason for combining $T$ with a second agent. However, bacteria possessing transmissible resistance to $\mathrm{T}$ are also characteristically resistant to sulphonamides. In a recent survey, Acar et al. (1977) found that 33 cultures containing transmissible resistance to $T$ were also resistant to sulphonamides.

These considerations argue strongly for the therapeutic use of $\mathrm{T}$ alonecertainly for the treatment of acute urinary-tract infections. It is hoped that the future introduction of any combination of dihydrofolic antagonsist, e.g., trimethoprim or tetroxoprim, with a sulphonamide is supported by clinicaltrial data demonstrating major advantages of the combination over either individual component. The recent introduction of a fixed combination of SZ and $\mathrm{T}$ has not been supported by such information. 


\section{SUMmaRY}

Sulphadiazine and trimethoprim in a wide range of concentrations were added to urine from patients with untreated urinary-tract infections. At therapeutic concentrations, the antibacterial activity of trimethoprim was not increased by the addition of sulphadiazine. Exposure of Escherichia coli to trimethoprim in urine was not associated with an increase in resistance to that agent. It was also not possible to select, in vitro, stable resistance to trimethoprim in sensitive cultures of $E$. coli.

At therapeutic levels in blood, trimethoprim and sulphadiazine singly produced mainly a bactericidal action on pathogens responsible for urinarytract infections. Sulphadiazine occasionally enhanced the effect of trimethoprim at subtherapeutic levels. These findings support the need for further evaluation of trimethoprim alone, rather than its use as a combination with a sulphonamide.

\section{REFERENCES}

ACar, J. F., Goldstein, F. W., Gerbaud, G. R. and Chabbert, Y. A., 1977. Plasmides de résistance au triméthoprime: transferabilité et groupes d'incompatabilité. Annals Microbiol., 128A, 41.

AizenberG, O. A., Samoylenko, I. I. and Fradkin, G. E., 1977. Role of the $\mathrm{B}^{+}$gene product in thymineless death and characteristics of this phenomenon in a thy ${ }^{-}$recB $^{-}$mutant of Escherichia coli K-12. Genetika, 13, 1988.

Amyes, S. G. B., AND SMIth J. T. 1978. Trimethoprim antagonists: effect of uridine on thymine and thymidine uptake in mineral salt medium. J. antimicrob. Chemother., 4, 415.

Anderson, J. D., Lacey R. W., Lewis, E. L. And Sellin, M. A. 1974. Failure to demonstrate an advantage in combining sulphamethoxazole with trimethoprim in an experimental model of urinary infection. J. clin. Path., 27,619.

Brumfitt, W. And Pursell, R., 1972. Double-blind trial to compare ampicillin, cephalexin, co-trimoxazole and trimethoprim in treatment or urinary infection. Br. med. J., 2, 673.

Buick, R. N. AND HaRris, W. J. 1975. Thymineless death in Bacillus subtilis. J. gen. Microbiol. 88, 115 .

Greenwood, D. ANd O'Grady, F. 1976. Activity and interaction of trimethoprim and sulphamethoxazole against. Escherichia coli. J. clin. Path., 29, 162.

Grey, D. and Hamilton-Miller, J. M. T. 1977. Sensitivity of Pseudomonas aeruginosa to sulphonamides and trimethoprim and the activity of the combination trimethoprim: sulphamethoxazole. J. med. Microbiol. 10, 273.

HitchinGs, G. H. 1970. Trimethoprim: biochemical basis for sulphonamide potentiation. $S$. Afr. med. J., suppl., 44, 1.

Kasanen, A., Kaarsalo, E., Hiltunen, R. and Soinı, V. 1974. Comparison of long-term low dosage nitrofurantoin, methenamine hippurate, trimethoprim and trimethoprim-sulphamethoxazole on the control of recurrent urinary-tract infection.. Ann. clin. Res. 6, 285.

Koch, U. J., SChumann, K. P., KüChler, R. AND KewITZ, H. 1973. Efficacy of trimethoprim, sulphamethoxazole, and the combination of both in acute urinary tract infections: clinical and pharmacological studies. Chemotherapy, 19, 314.

LACEY, R. W. 1978. The suppression of the appearance of bacterial mutants by combined antibacterial therapy. J. antimicrob. Chemother., 4, 391.

LeWIS, E. L., ANDERSON, J. D. AND LACEY, R. W. 1974. A reappraisal of the antibacterial action of cotrimoxazole in vitro. J. clin. Path., $27,87$.

Männistö, P., Tuomisto, J., SARIs, N-E. And Lehtinen, T. 1973. Pharmacokinetic studies with trimethoprim and different doses of sulphadiazine in healthy human subjects. Chemotherapy, 19, 289. 
NotTeBrock, H. AND Then, R. 1977. Thymidine concentrations in serum and urine of different animal species and man. Biochem. Pharmac., 26, 2175.

Pinney, R. J., Jacob, A. E., Hedges, R. W. and Smith, J. T. 1977. Dislodgement and thymineless elimination of N-group plasmids. Gentet. Res., 30, 21.

Samanta, H. K. and BhattacharJeE, S. B. 1977. Thymineless death in Escherichia coli. $Z$. Naturf., 32, 835.

STOKES, A. AND LACEY, R. W. 1978. Effect of thymidine on activity of trimethoprim and sulphamethoxazole. J. clin. Path., 31, 165.

Towner, K. J., Pearson, N. J., Cattell, W. R. and O'Grady, F. 1978. Chromosomal resistance to trimethoprim. Lancet $1,1371$.

Tuomisto, J., Kasanen, A. And RenKonen, O-V. 1977. Sulphadiazine-trimethoprim combinations in the treatment of urinary tract infections. Chemotherapy, 23, 337. 